\title{
How to appraise quantitative research
}

\section{Xabi Cathala, ${ }^{1}$ Calvin Moorley ${ }^{2}$}

$10.1136 /$ eb-2018-102996

${ }^{1}$ Institute of Vocational Learning, School of Health and Social Care, London South Bank University, London, UK

${ }^{2}$ Nursing Research and Diversity in Care, School of Health and Social Care, London South Bank University, London, UK

\section{Correspondence to:}

\section{Mr Xabi Cathala, Institute of}

Vocational Learning, School of Health and Social Care, London South Bank University London UK ; cathalax@lsbu.ac.uk and Dr Calvin Moorley, Nursing Research and Diversity in Care, School of Health and Social Care, London South Bank University, London SE1 OAA, UK; Moorleyc@ Isbu.ac.uk

\section{Introduction}

Some nurses feel that they lack the necessary skills to read a research paper and to then decide if they should implement the findings into their practice. This is particularly the case when considering the results of quantitative research, which often contains the results of statistical testing. However, nurses have a professional responsibility to critique research to improve their practice, care and patient safety. ${ }^{1}$ This article provides a step by step guide on how to critically appraise a quantitative paper.

\section{Title, keywords and the authors}

The title of a paper should be clear and give a good idea of the subject area. The title should not normally exceed 15 words $^{2}$ and should attract the attention of the reader. ${ }^{3}$ The next step is to review the key words. These should provide information on both the ideas or concepts discussed in the paper and the subject area addressed in the article. These first steps can often influence your decision whether to read the entire paper.

The authors' names may not mean much, but knowing the following will be helpful:

- Their position, for example, academic, researcher or healthcare practitioner.

- Their qualification, both professional, for example, a nurse or physiotherapist and academic (eg, degree, masters, doctorate).

This can indicate how the research has been conducted and the authors' competence on the subject. Basically, do you want to read a paper on quantum physics written by a plumber?

\section{Abstract}

The abstract is a resume of the article and should contain:

- Introduction.

- Research question/hypothesis.

- Methods including sample design, tests used and the statistical analysis (of course! Remember we love numbers).

- Main findings.

- Conclusion.

The subheadings in the abstract will vary depending on the journal. An abstract should not usually be more than 300 words but this varies depending on specific journal requirements. If the above information is contained in the abstract, it can give you an idea about whether the study is relevant to your area of practice. However, before deciding if the results of a research paper are relevant to your practice, it is important to review the overall quality of the article. This can only be done by reading and critically appraising the entire article.

\section{The introduction}

A well-structured introduction should gain the attention of the reader by making the subject area interesting. ${ }^{4}$
The choice of subject should be clearly explained. The introduction should arouse your interest and curiosity and answer the question why should I bother reading this paper? Normally, the research question, aim, hypothesis and null hypothesis will be clearly stated in the introduction. An example of a hypothesis and null hypothesis can be seen in box 1 .

\section{Background/literature review}

The literature review should include reference to recent and relevant research in the area. It should summarise what is already known about the topic and why the research study is needed and state what the study will contribute to new knowledge. ${ }^{5}$ The literature review should be up to date, usually 5-8 years, but it will depend on the topic and sometimes it is acceptable to include older (seminal) studies.

\section{Methodology}

In quantitative studies, the data analysis varies between studies depending on the type of design used. For example, descriptive, correlative or experimental studies all vary. A descriptive study will describe the pattern of a topic related to one or more variable. ${ }^{6}$ A correlational study examines the link (correlation) between two variables ${ }^{7}$ and focuses on how a variable will react to a change of another variable. In experimental studies, the researchers manipulate variables looking at outcomes $^{8}$ and the sample is commonly assigned into different groups (known as randomisation) to determine the effect (causal) of a condition (independent variable) on a certain outcome. This is a common method used in clinical trials.

There should be sufficient detail provided in the methods section for you to replicate the study (should you want to). To enable you to do this, the following sections are normally included:

Box 1 Example: the effect of paracetamol on levels of pain

- My hypothesis is that $\mathrm{A}$ has an effect on $B$, for example, paracetamol has an effect on levels of pain.

- My null hypothesis is that $A$ has no effect on $B$, for example, paracetamol has no effect on pain.

- My study will test the null hypothesis and if the null hypothesis is validated then the hypothesis is false (A has no effect on $B)$. This means paracetamol has no effect on the level of pain. If the null hypothesis is rejected then the hypothesis is true (A has an effect on B). This means that paracetamol has an effect on the level of pain. 
- Overview and rationale for the methodology.

- Participants or sample.

- Data collection tools.

- Procedure.

- Methods of data analysis.

- Ethical issues.

Data collection should be clearly explained and the article should discuss how this process was undertaken. Data collection should be systematic, objective, precise, repeatable, valid and reliable. Any tool (eg, a questionnaire) used for data collection should have been piloted (or pretested and/or adjusted) to ensure the quality, validity and reliability of the tool. ${ }^{9}$ The participants (the sample) and any randomisation technique used should be identified. The sample size is central in quantitative research, as the findings should be able to be generalised for the wider population. ${ }^{10}$ The data analysis can be done manually or more complex analyses performed using computer software sometimes with advice of a statistician. From this analysis, results like mode, mean, median, $\mathrm{p}$ value, $\mathrm{CI}$ and so on are always presented in a numerical format.

\section{Results}

The author(s) should present the results clearly. These may be presented in graphs, charts or tables alongside some text. You should perform your own critique of the data analysis process; just because a paper has been published, it does not mean it is perfect. Your findings may be different from the author's. Through critical analysis the reader may find an error in the study process that authors have not seen or highlighted. These errors can change the study result or change a study you thought was strong to weak. To help you critique a quantitative research paper, some guidance on understanding statistical terminology is provided in table 1.

Quantitative studies examine the relationship between variables, and the $p$ value illustrates this objectively. ${ }^{11}$ If the $p$ value is less than 0.05 , the null hypothesis is rejected and the hypothesis is accepted and the study will say there is a significant difference. If the $p$ value is more than 0.05 , the null hypothesis is accepted then the hypothesis is rejected. The study will say there is no significant difference. As a general rule, a $\mathrm{p}$ value of less than 0.05 means, the hypothesis is accepted and if it is more than 0.05 the hypothesis is rejected.

The $\mathrm{CI}$ is a number between 0 and 1 or is written as a per cent, demonstrating the level of confidence the reader can have in the result. ${ }^{12}$ The $\mathrm{CI}$ is calculated by subtracting the $p$ value to $1(1-p)$. If there is a $p$ value of 0.05 , the CI will be $1-0.05=0.95=95 \%$. A CI over $95 \%$ means, we can be confident the result is statistically

\footnotetext{
Table 1 Some basic guidance for understanding statistics

P values P means probability. Therefore, it represents the probability of an event occurring. It evaluates how good the data supports the null hypothesis.

- High p values: your data supports the null hypothesis. This is generally shown as $p$ value $>0.05$.

- Low p values: your data does not support the null hypothesis. This is generally shown as $p$ value $<0.05$.

$\mathrm{Cl} \quad$ The $\mathrm{Cl}$ is a value that we are fairly certain our sample mean lies within. Normally measured at $95 \%$. If samples were taken on numerous occasions, we would expect that $95 \%$ would contain the sample mean. Five per cent of the intervals would not contain the mean.

- A $95 \% \mathrm{Cl}$ has a 0.95 probability of containing the population mean.

Correlation The correlation coefficient measures the strength and direction of the relationship between two variables. The coefficients range of values for the correlation coefficient (called $r$ ) is between -1.0 and 1.0.

- A correlation of -1.0 shows a strong negative relationship.

- A correlation of 1.0 shows a strong positive correlation.

- A correlation of 0.0 shows no relationship between the two variables.

The stronger the correlation, the closer the $r$ will be to \pm 1 . If $r$ is positive, the variables are directly related. If $r$ is negative, the variables are inversely related. The significance of the relationship is reported as probability ( $p$ values) telling the unlikelihood of no relationship (correlation coefficient r) in the sample.

- The smaller the $p$ value, the more significant the relationship.

Mean The mean, often called the average, is a measure of central tendency. It is the sum of all the values in a data set divided by the number of samples. For example, if this is a data set:

$1,1,2,2,2,2,3,3,4,4,5,5,5$

the mean is ' 3 ' (39/13). It is useful in describing the sample characteristics such as age.

Mode The mode is a measure of central tendency (average). It is the value that appears the most. For example, if this is a data set:

$1,1,2,2,2,2,3,3,4,4,5,5,5$

the mode is ' 2 '. There can be more than one mode which is known as bimodal.

- The mode is used for categorical data and is helpful when we need to know the most common or popular category.

Median The median is a measure of central tendency (average). It is the middle value in a data set arranged in numerical order. For example, if this is a data set:

$1,1,2,2,2,2,3,3,4,4,5,5,5$

the median (middle) number is 3. You have as many numbers on one side than the other of the median number.

- If you have an even set of sample data average the middle two this number will be your median.

SD The SD is a measure of how your data are spread around the mean.

- If your SD is small, your data are spread close to your mean value.

- When the SD is large, your data are spread away from the mean value.
} 


\begin{tabular}{|c|c|c|}
\hline Critiquing sub headings & Areas to consider & Notes \\
\hline Believability and credibility & $\begin{array}{l}\text { Title: Is it clear, what is the length, is it accurate? } \\
\text { Keywords: Are the key words reflective of the paper? } \\
\text { Author: What are the author's credentials, do they instil credibility and trustworthiness? } \\
\text { Abstract: Is the abstract present, and does it conform to an acceptable convention? }\end{array}$ & 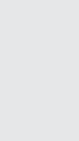 \\
\hline $\begin{array}{l}\text { Hypothesis, research } \\
\text { question, aims }\end{array}$ & $\begin{array}{l}\text { Hypothesis: Is the hypothesis or null hypothesis stated? } \\
\text { Research question: Is the question clear or are there clear aims and objectives? }\end{array}$ & $\otimes$ \\
\hline Robustness and rigour & $\begin{array}{l}\text { Literature review: Is the literature used peer-reviewed, current and does it support } \\
\text { the topic of the paper? Sample: Is the sample appropriate, and does the size allow } \\
\text { generalisation? } \\
\text { Ethics: Does the study have ethical approval and if not, is this adequately justified? }\end{array}$ & $\otimes$ \\
\hline Methodology & $\begin{array}{l}\text { Design: Is the research design clearly stated? } \\
\text { Data collection: Is the data collection process clear including recruitment and consent? } \\
\text { Reliability and validity: Is the reliability and validity of the data collection adequately } \\
\text { described? Have any tools been piloted or pretested? }\end{array}$ & $\otimes$ \\
\hline Data analysis and results & $\begin{array}{l}\text { Data analysis: Did the researcher follow the steps of data analysis and is how the data } \\
\text { was managed clear? } \\
\text { Results: Are the results accurate and presented in the correct format? }\end{array}$ & $\nabla$ \\
\hline $\begin{array}{l}\text { Discussion, } \\
\text { recommendations and } \\
\text { conclusion }\end{array}$ & $\begin{array}{l}\text { Discussion: Is there a logical flow and is the data placed in context of the study and } \\
\text { literature reviewed? Has the rejection or acceptance of the hypothesis been discussed } \\
\text { and developed? Does the study consider the strengths and limitations of its findings? } \\
\text { Is the clinical significance or application to practice identified? Are their future } \\
\text { recommendations for practice? }\end{array}$ & $\otimes$ \\
\hline
\end{tabular}

significant. A CI below 95\% means, the result is not statistically significant. The $\mathrm{p}$ values and $\mathrm{CI}$ highlight the confidence and robustness of a result.

\section{Discussion, recommendations and conclusion}

The final section of the paper is where the authors discuss their results and link them to other literature in the area (some of which may have been included in the literature review at the start of the paper). This reminds the reader of what is already known, what the study has found and what new information it adds. The discussion should demonstrate how the authors interpreted their results and how they contribute to new knowledge in the area. Implications for practice and future research should also be highlighted in this section of the paper.

A few other areas you may find helpful are:

- Limitations of the study.

- Biases.

- Conflicts of interest.

Table 2 provides a useful tool to help you apply the learning in this paper to the critiquing of quantitative research papers.

Correction notice This article has been updated since its original publication to update $\mathrm{p}$ values from 0.5 to 0.05 throughout.

Competing interests None declared.

Patient consent Not required.

Provenance and peer review Commissioned; internally peer reviewed.
( Author(s) (or their employer(s)) 2018. No commercial re-use. See rights and permissions. Published by BMJ.

\section{References}

1. Nursing and Midwifery Council, 2015. The code: standard of conduct, performance and ethics for nurses and midwives https://www.nmc.org.uk/globalassets/sitedocuments/nmcpublications/nmc-code.pdf (accessed 21.8.18).

2. Polit DF, Beck CT. Study guide for essentials of nursing research: appraising evidence for nursing practice: Lippincott Williams \& Wilkins, 2013.

3. Parahoo K. Nursing research: Principles, process and issues. 3rd ed. Hampshire: Macmillan Publishers Limited, 2014.

4. Gerrish K, Lathlean J. The research process in nursing. 7th ed. Chichester, West Sussex: Wiley Blackwell, 2015.

5. Smith J, Noble H. Reviewing the literature. Evid Based Nurs 2016;19:2-3.

6. Moorley C, Cahill S, Tunariu A, et al. Impact of stroke: a functional, psychological report of an inner-city multiracial population. Primary Health Care 2014;24:26-34.

7. Grove SK, Burns N, Gray J. The practice of nursing research: appraisal, synthesis, and generation of evidence: Elsevier Health Sciences, 2012.

8. Punch KF. Introduction to social research: quantitative and qualitative approaches: Sage, 2013.

9. Heale R, Twycross A. Validity and reliability in quantitative studies. Evid Based Nurs 2015;18:66-7.

10. Shorten A, Moorley C. Selecting the sample. Evid Based Nurs 2014;17:32-3.

11. Forbes DA. What is a p value and what does it mean? Evid Based Nurs 2012;15:34.

12. Clarke J. What is a CI? Evid Based Nurs 2012;15:66. 


\section{Correction: How to appraise quantitative research}

Cathala X, Moorley C. How to appraise quantitative research. Evid Based Nurs 2019;21:99-101. doi: 10.1136/ eb-2018-102996.

Correction:

The previous version of this article contained an error. On page 2 the following text where $p$ value of 0.5 is mentioned, this should read as 0.05 not 0.5 .

The corrected text is available below:

Quantitative studies examine the relationship between variables, and the $\mathrm{p}$ value illustrates this objectively. 11 If the $p$ value is less than 0.05 , the null hypothesis is rejected and the hypothesis is accepted and the study will say there is a significant difference. If the $p$ value is more than 0.05 , the null hypothesis is accepted then the hypothesis is rejected. The study will say there is no significant difference. As a general rule, a p value of less than 0.05 means, the hypothesis is accepted and if it is more than 0.05 the hypothesis is rejected.

Similarly, in Table 1, occurences of p value 0.5 should read as 0.05 .

The original version of this article has been updated to reflect this change.

( Author(s) (or their employer(s)) 2019. No commercial re-use. See rights and permissions. Published by BMJ.

(A) Check for updates

Evid Based Nurs 2019;22:62. doi:10.1136/ebnurs-2018-102996corr1 